\title{
Article
}

\section{Research on the Response Characteristics of Vanadium Pentoxide Film to the Irradiation of Ultrafast Pulsed Laser}

\author{
Qianqian Shi ${ }^{1,2}$, Guodong Zhang ${ }^{3}$, Yuheng Wang ${ }^{4}$, Yu Lan ${ }^{1,2}$, Jiang Wang ${ }^{3}$ and Guanghua Cheng ${ }^{3, *(1)}$ \\ 1 State Key Laboratory of Transient Optics and Photonics, Xi'an Institute of Optics and Precision Mechanics, \\ Chinese Academy of Sciences, Xi'an 710119, China; shiqianqian@opt.cn (Q.S.); lanyu2017@opt.cn (Y.L.) \\ 2 University of Chinese Academy of Sciences, Beijing 100049, China \\ 3 School of Artificial Intelligence, Optics and Electronics (iOPEN), Northwestern Polytechnical University, \\ Xi'an 710072, China; guodongzhang@nwpu.edu.cn (G.Z.); wjiang@nwpu.edu.cn (J.W.) \\ 4 Research Center of Semiconductor Lighting and Information Engineering Technology, \\ South China University of Technology, Guangzhou 510641, China; imtree@126.com \\ * Correspondence: guanghuacheng@nwpu.edu.cn; Tel.: +86-137-0022-9561
}

check for updates

Citation: Shi, Q.; Zhang, G.; Wang, Y.; Lan, Y.; Wang, J.; Cheng, G.

Research on the Response

Characteristics of Vanadium

Pentoxide Film to the Irradiation of Ultrafast Pulsed Laser. Nanomaterials 2021, 11, 2078. https://doi.org/ $10.3390 /$ nano11082078

Academic Editor:

Christophe Detavernier

Received: 29 July 2021

Accepted: 12 August 2021

Published: 16 August 2021

Publisher's Note: MDPI stays neutral with regard to jurisdictional claims in published maps and institutional affiliations.

Copyright: (C) 2021 by the authors. Licensee MDPI, Basel, Switzerland. This article is an open access article distributed under the terms and conditions of the Creative Commons Attribution (CC BY) license (https:/ / creativecommons.org/licenses/by/ $4.0 /)$.

\begin{abstract}
Vanadium pentoxide $\left(\mathrm{V}_{2} \mathrm{O}_{5}\right)$ is the most stable phase among many transition metal vanadium oxides, and has already been widely used in many fields. In this study, the morphological, structural, and optical responses of $\mathrm{V}_{2} \mathrm{O}_{5}$ film to ultrafast laser irradiation was investigated. The third-order nonlinear optical properties of $\mathrm{V}_{2} \mathrm{O}_{5}$ film were measured by common Z-scan technique, and the results showed that $\mathrm{V}_{2} \mathrm{O}_{5}$ film has self-defocusing and saturable absorption characteristics. The third-order nonlinear absorption coefficient and nonlinear refractive index were calculated to be $-338 \mathrm{~cm} / \mathrm{GW}$ and $-3.62 \times 10^{-12} \mathrm{~cm}^{2} / \mathrm{W}$, respectively. The tunable saturated absorption with modulation depth ranging from $13.8 \%$ to $29.3 \%$ was realized through controlling the thickness of vanadium pentoxide film. $\mathrm{V}_{2} \mathrm{O}_{5}$ film was irradiated by ultrafast laser with variable pulse energy, and the morphological and structural responses of the $\mathrm{V}_{2} \mathrm{O}_{5}$ to the laser with different energy densities were investigated. The irreversible morphological and structural responses of $\mathrm{V}_{2} \mathrm{O}_{5}$ films to ultrafast laser irradiation was analyzed using the phase-contrast microscope and Raman spectrum. The chemical structure change from $\mathrm{V}_{2} \mathrm{O}_{5}$ to $\mathrm{V}_{6} \mathrm{O}_{13}$ was considered the main reason for refractive index modification.
\end{abstract}

Keywords: vanadium pentoxide; ultrafast laser irradiation; Z-scan technique; nonlinear optical

\section{Introduction}

Vanadium oxides are known to have the unique property of semiconductor-metal reversible phase transitions during long-pulsed laser irradiation, thus having a wide range of potential applications in optical, electronic, and photoelectric devices [1]. There are more than ten stoichiometric formulae for vanadium oxides from the lowest $\mathrm{VO}$ phase to the highest $\mathrm{V}_{2} \mathrm{O}_{5}$ phase [2]. Since the vanadium atom in $\mathrm{V}_{2} \mathrm{O}_{5}$ has the highest valence, $\mathrm{V}_{2} \mathrm{O}_{5}$ possesses the most stable chemical properties among these vanadium oxides. $\mathrm{V}_{2} \mathrm{O}_{5}$ has a reversible first-order phase transition property, and its phase transition temperature is about $257^{\circ} \mathrm{C}$ [3]. In addition, $\mathrm{V}_{2} \mathrm{O}_{5}$ has a unique layered structure, which makes it a very promising material.

Compared to bulk materials, nanofilms exhibit many excellent electrical and optical properties such as high thermal conductivity, high light transmittance, outstanding nonlinear optical properties, etc. [4]. Therefore, the best utilization and application form of $\mathrm{V}_{2} \mathrm{O}_{5}$ is the two-dimensional film. At present, there are many techniques for preparing thin film, such as magnetron sputtering, Sol-gel, atom layered deposition (ALD), and hydrothermal [5-8]. The photoelectric properties of thin films are slightly different due to the different preparation techniques and technological parameters. In our experiment, silica coating was used to improve the stability of the $\mathrm{V}_{2} \mathrm{O}_{5}$ film [9]. 
With the appearance and flourishing of the ultrafast laser, more researchers are now involved in the study of the interaction between ultrafast laser and material [10-12]. Due to very high peak power at focal region, the advantage of nonlinear optical absorption and localized energy deposition has conferred a unique potential upon ultrafast laser pulses to structure and modify optical material. Some transition metal oxides possess excellent nonlinear optical properties, which can be controlled by changing the samples' shape and thickness, such as $\mathrm{VO} x, \mathrm{WS}_{2}$, and $\mathrm{MoS}_{2}$ [13-15]. Although there are several works related to the optical and electrical properties of $\mathrm{V}_{2} \mathrm{O}_{5}$ thin films [16-18], few studies have been conducted on the performance response of $\mathrm{V}_{2} \mathrm{O}_{5}$ induced by ultrafast laser.

In this work, the response characteristics of $\mathrm{V}_{2} \mathrm{O}_{5}$ film to the irradiation of ultrafast pulsed laser is carefully studied. $\mathrm{V}_{2} \mathrm{O}_{5}$ films with different thicknesses were prepared by radio frequency (RF) magnetron sputtering technology. The Z-scan setup equipped with the Yb-doped fiber Chirped Pulsed Amplification (CPA) laser system was used to characterize the nonlinear optical properties of the $\mathrm{V}_{2} \mathrm{O}_{5}$ film. In addition, the laser, with different pulse energies, is used to irradiate the $\mathrm{V}_{2} \mathrm{O}_{5}$ film, which is a supplementary process to the Z-scan experiment. For analyzing the morphological and structural responses of $\mathrm{V}_{2} \mathrm{O}_{5}$ film to the ultrafast laser irradiation, Scanning Electron Microscopy, Phase-Contrast Microscopy, and the Raman spectrum were utilized in the experiment.

\section{Materials and Methods}

\subsection{Film Preparation}

The radio frequency ( $R F)$ magnetron sputtering was used to deposite vanadium pentoxide films on the $1 \times 1 \mathrm{~cm}^{2}$ R-plane double-sided polished sapphire substrates. The temperature for film deposition was set as $395^{\circ} \mathrm{C}$ and the radio frequency power was kept at $200 \mathrm{~W}$. The working pressure was kept at $0.7 \mathrm{~Pa}$, while the $\mathrm{Ar}$ and $\mathrm{O}_{2}$ flow were set at $98 \mathrm{sccm}$ and $2.1 \mathrm{sccm}$, respectively. By controlling the deposition time, the vanadium oxide films with different thicknesses were prepared. After deposition, samples were annealed at $395{ }^{\circ} \mathrm{C}$ in situ in the Ar-filled chamber for $40 \mathrm{~min}$. In order to prevent the films from being oxidized, a $24 \mathrm{~nm}$ thick silicon oxide protective film was coated onto the sample surface.

\subsection{Picosecond Laser Processing}

The Yb-doped fiber Chirped Pulsed Amplification (CPA) laser system, operating at a wavelength of $515 \mathrm{~nm}$ with pulse duration of $1.2 \mathrm{ps}$ and repetition rate of $100 \mathrm{KHz}$, was used to irradiate $\mathrm{V}_{2} \mathrm{O}_{5}$ thin films under different pulse energies. Through an objective lens (Mitutoyo), with numerical aperture (NA) of 0.42 , the ultrafast laser was focused onto the vanadium oxide films, which were placed on a three-dimensional stage (Aerotech ANT95). Then, the ultrafast laser pulses with different pulse energies were used to selectively modify spaces on the vanadium oxide films in a single shot regime. The separation distance between adjacent laser-modified regions was set as $10 \mu \mathrm{m}$ in the experiment.

\subsection{Characterization}

The surface morphology of the $\mathrm{V}_{2} \mathrm{O}_{5}$ thin film and the laser-induced modification were studied by Scanning Electron Microscopy (SEM, FEI, Verios G4, Hillsboro, Oregon, USA), Atom Force Microscopy (AFM, Bruker, Dimension Icon, Mannheim, Germany), X-ray photoelectron spectroscopy (XPS, Shimadzu, Kratos Ultra DLD, Kyoto, Japan), and Phase-Contrast Microscopy (Olympus, BX51, Tokyo, Japan). The UV-Vis-NIR transmittance spectrum was measured by the spectrophotometer (Shimadzu, UV-3150, Kyoto, Japan) at room temperature. The modifications in chemical structure induced under different pulse energies were characterized using the Confocal Micro-Raman spectrometer (WITec, Alpha300R, Ulm, Germany) with excitation laser of $532 \mathrm{~nm}$. We expected to see a larger nonlinear effect at longer wavelength; therefore, the Z-scan setup equipped with the $\mathrm{Yb}$ doped fiber Chirped Pulsed Amplification (CPA) laser system operating at a wavelength of $1030 \mathrm{~nm}$ was used to characterize the nonlinear optical properties of the $\mathrm{V}_{2} \mathrm{O}_{5}$ thin film. 


\section{Results and Discussion}

\subsection{Surface Morphology and Component}

The surface morphology of the synthesized $\mathrm{V}_{2} \mathrm{O}_{5}$ thin film was characterized using the AFM, as shown in Figure 1a. It can be seen from the three-dimensional AFM image that the prepared $\mathrm{V}_{2} \mathrm{O}_{5}$ thin film on R-plane sapphire substrate possesses a superior nanorod microcrystalline structure composed of smaller nanoparticles. The roughness of the film prepared was $2.64 \mathrm{~nm}$. For controlling the thickness of the $\mathrm{V}_{2} \mathrm{O}_{5}$ film, the sputtering time during the material deposition process was regulated, ranging from $10 \mathrm{~min}$ to $30 \mathrm{~min}$. The thickness of the $\mathrm{V}_{2} \mathrm{O}_{5}$ film was characterized by the SEM and step profiler. The results are concluded as shown in Figure 1b; the thickness of these five films were $45.4 \mathrm{~nm}, 56.9 \mathrm{~nm}$, $68.6 \mathrm{~nm}, 79.6 \mathrm{~nm}$, and $90.4 \mathrm{~nm}$, respectively. It can be derived that the increase of film thickness was positively linear with the sputtering time. The deposition rate was about $2.25 \mathrm{~nm} / \mathrm{min}$.
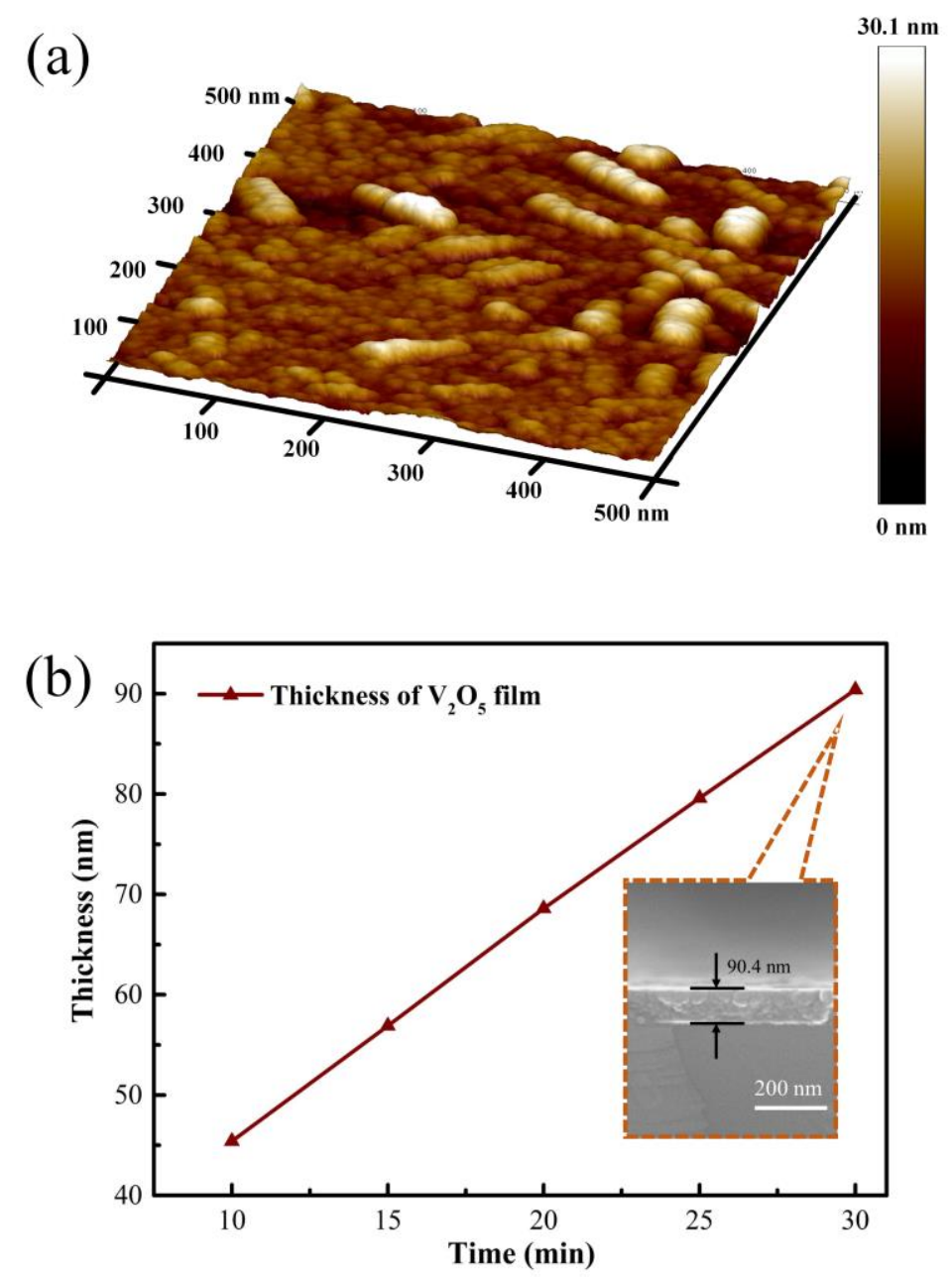

Figure 1. Three-dimensional morphology of $\mathrm{V}_{2} \mathrm{O}_{5}$ thin film on R-plane sapphire substrate (a), the synthesized $\mathrm{V}_{2} \mathrm{O}_{5}$ film with different thickness and SEM cross section image (b).

The valence state and composition information of the sample were obtained by XPS, and the results are shown in Figure 2. The binding energy for $V 2 p_{3 / 2}$ peak was $517.039 \mathrm{eV}$, which corresponded to the characteristic binding energy of $\mathrm{V}^{5+}$, proving that the film prepared is $\mathrm{V}_{2} \mathrm{O}_{5}$ film [19]. 

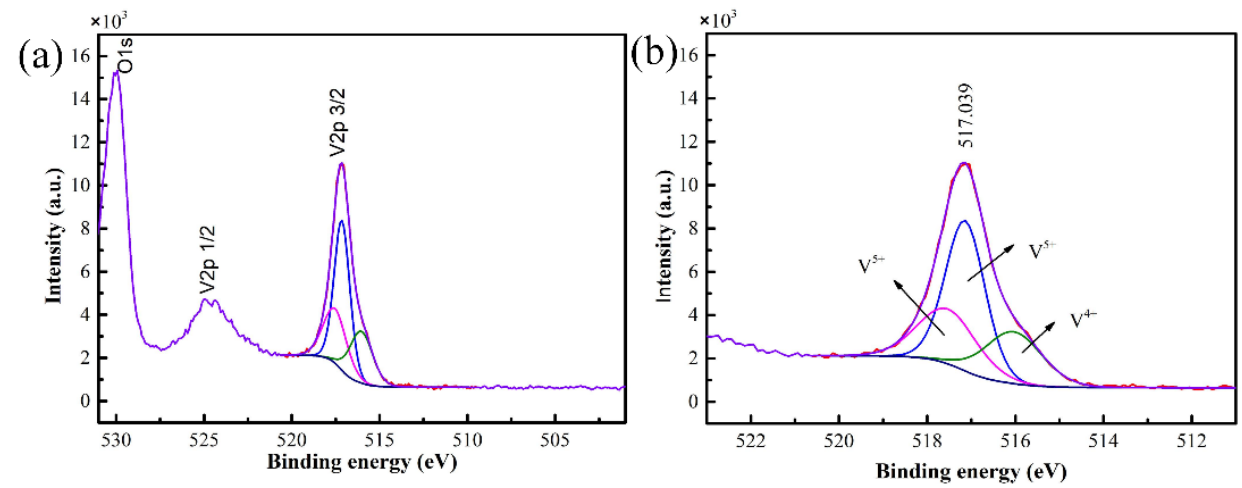

Figure 2. XPS spectra of the $\mathrm{V}_{2} \mathrm{O}_{5}$ film (a) and curve fitting of $\mathrm{V} 2 \mathrm{p}_{3 / 2}$ spectra (b).

\subsection{Nonlinear Optical Properties}

Then, the Z-scan method was taken to measure the nonlinear optical properties of the synthesized $\mathrm{V}_{2} \mathrm{O}_{5}$ thin film [20]. The laser source used in the Z-scan measurement had a wavelength of $1030 \mathrm{~nm}$, the pulse duration was $1.2 \mathrm{ps}$, and the input pulse energy was $4.1 \mu \mathrm{J}$. The laser beam was focused through a lens with a focal length of $200 \mathrm{~mm}$, and the Rayleigh length $Z_{R}$ and linear transmittance $S$ were $1.15 \mathrm{~mm}$ and 0.2 , respectively. For the open-aperture Z-scan mode, the normalized transmittance is described as [21]

$$
T_{N}(z, S=1)=\sum_{m=0}^{\infty} \frac{\left[-q_{0}\right]^{m}}{(m+1)^{3 / 2}}
$$

where $q_{0}$ is the free factor, which is defined as

$$
\mathrm{q}_{0}=\frac{\beta_{e f f} I_{0} L_{e f f}}{\left(1+z^{2} / z_{R}^{2}\right)}
$$

$\beta_{\text {eff }}$ is the third order nonlinear absorption coefficient, $I_{0}$ is the intensity of laser beam at focus position, and $L_{\text {eff }}$ is the effective thickness of the sample, which can be calculated by the following equation:

$$
L_{e f f}=\frac{1-\mathrm{e}^{(-\alpha L)}}{\alpha}
$$

where $L$ is the thickness of the film, $\alpha$ is the linear absorption coefficient, which is defined as

$$
\alpha=\frac{\log \left(\frac{1}{T}\right)}{d}
$$

where $T$ is the linear transmittance, and $d$ is the thickness of the sample.

The third order nonlinear refractive coefficient $\gamma$ can be given by the equation [22]:

$$
\begin{gathered}
\gamma=\frac{\lambda \Delta \phi_{0}}{2 \pi L_{e f f} I_{0}} \\
\Delta T_{p-v}=0.406(1-S)^{0.25} \Delta \phi_{0}
\end{gathered}
$$

where $\Delta \phi_{0}$ is the axial phase shift at the focus, and $\Delta T_{p-v}$ is the difference value between the normalized transmittance peak and valley. Closed-aperture normalized transmittance can be simplified as [21]

$$
T(z)=1-\frac{4 x \Delta \phi_{0}}{\left(x^{2}+9\right)\left(x^{2}+1\right)}
$$

where $x=Z / Z_{R}, Z_{R}$ is the Rayleigh length.

In order to get the nonlinear coefficient of the $\mathrm{V}_{2} \mathrm{O}_{5}$ thin film, open-aperture and closed-aperture Z-scan measurements were conducted. The open-aperture Z-scan curve 
of the $\mathrm{V}_{2} \mathrm{O}_{5}$ film with thickness of $90 \mathrm{~nm}$, as shown in Figure 3a, indicates that $\mathrm{V}_{2} \mathrm{O}_{5}$ thin film had a negative nonlinear absorption coefficient. It is obvious that with increasing irradiation intensity, the sample exhibited a saturable absorption. For the closed-aperture Z-scan characterization, as shown in Figure $3 b$, the normalized transmittance presented a peak profile followed with a valley, which was attributed to the self-defocusing process, indicating that the film had a negative nonlinear refractive coefficient. As the saturable absorption enhanced the nonlinear transmittance, the valley was well suppressed for closedaperture Z-scan characterization. Equation (1) was used to fit the open-aperture curve to obtain the value of $\mathrm{q}_{0}$, and accordingly calculated the nonlinear absorption coefficient of $-338 \mathrm{~cm} / \mathrm{GW}$. Moreover, the third-order nonlinear refractive coefficient was calculated to be $-3.62 \times 10^{-12} \mathrm{~cm}^{2} / \mathrm{W}$ by combining the Equation (2) with (3).
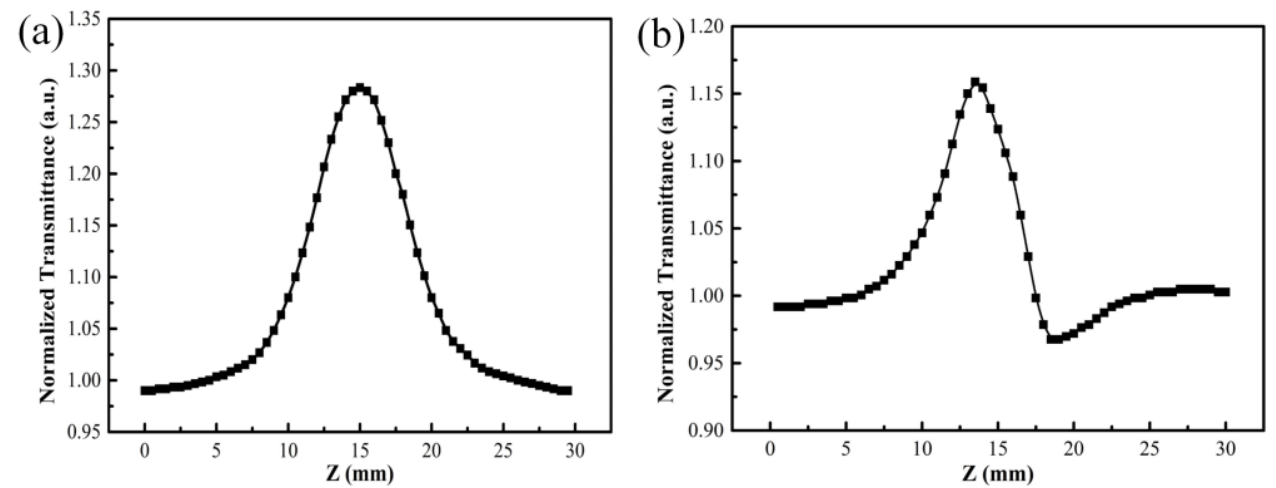

Figure 3. Open-aperture (a) and closed-aperture (b) Z-scan curves of $\mathrm{V}_{2} \mathrm{O}_{5}$ thin film with thickness of $90 \mathrm{~nm}$.

Furthermore, the linear and nonlinear absorption properties of the $\mathrm{V}_{2} \mathrm{O}_{5}$ films with different thicknesses were investigated as shown in Figure 4. From the transmittance spectra of the films, as shown in Figure 4a, it can be derived that the transmittance of films decreased with increasing film thickness. The transmittance of the $\mathrm{V}_{2} \mathrm{O}_{5}$ films at the wavelength of $1030 \mathrm{~nm}$ was characterized to decrease from $73 \%$ to $62.5 \%$ when film thickness increased from $45 \mathrm{~nm}$ to $90 \mathrm{~nm}$. The saturated absorption properties of $\mathrm{V}_{2} \mathrm{O}_{5}$ films with different thicknesses were characterized by the open-aperture Z-scan setup, as shown in Figure $4 \mathrm{~b}$. Based on the transmittance curves, the modulation depth of the $\mathrm{V}_{2} \mathrm{O}_{5}$ films with different thickness was calculated. As for the $45 \mathrm{~nm} \mathrm{~V}_{2} \mathrm{O}_{5}$ film, the modulation depth had a value of $13.8 \%$. When the thickness was further increased, the modulation depth exhibited an apparent increase. The maximum modulation depth of $\mathrm{V}_{2} \mathrm{O}_{5}$ films obtained at a thickness of $90 \mathrm{~nm}$ was about $29.3 \%$. Since the strength of the saturable absorption effect depended on the amount of the nonlinear materials, we see in Figure $4 \mathrm{~b}$ a linear dependence of transmittance on the film thickness.

(a)

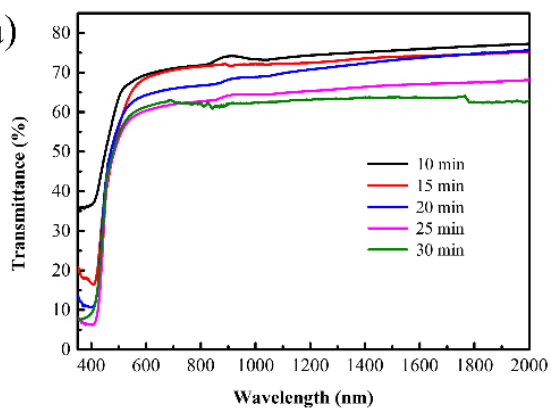

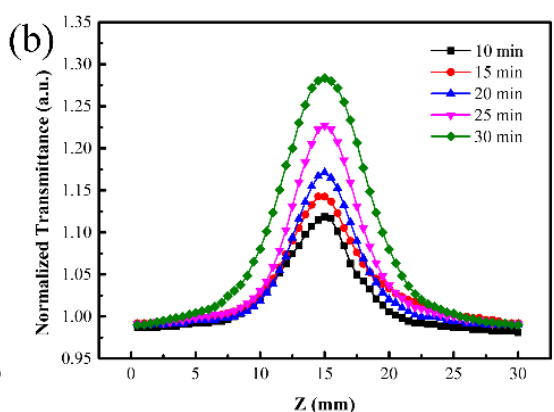

Figure 4. Transmittance spectra (a) and the open-aperture Z-scan curves (b) of the $\mathrm{V}_{2} \mathrm{O}_{5}$ film with different thicknesses. 
The relevant parameters of the nonlinear coefficient of the five $\mathrm{V}_{2} \mathrm{O}_{5}$ films with different thicknesses are listed in Table 1.

Table 1. Z-scan experimental data results.

\begin{tabular}{cccc}
\hline Sample & $\mathbf{T}_{\mathbf{1 0 3 0}} \mathbf{( \% )}$ & $\mathbf{B}_{\mathbf{e f f}} \mathbf{( c m / G W )}$ & $\boldsymbol{\Delta} \mathbf{T}(\mathbf{\%})$ \\
\hline $10 \mathrm{~min}$ & 73.58 & -141 & 13.8 \\
$15 \mathrm{~min}$ & 72.05 & -170 & 15 \\
$20 \mathrm{~min}$ & 68.73 & -204 & 18.1 \\
$25 \mathrm{~min}$ & 64.43 & -271 & 23.4 \\
$30 \mathrm{~min}$ & 62.23 & -338 & 29.3 \\
\hline
\end{tabular}

\subsection{Phase Contrast Microscope}

The positive phase contrast microscope was used to characterize the morphology and index changes induced by the ultrafast pulsed laser. Figure 5 shows the phase-contrast images of $\mathrm{V}_{2} \mathrm{O}_{5}$ irradiated by the ultrafast laser with different pulse energies. The black region represents the positive refractive index change, while the white region represents the negative refractive index change. It can be seen that the refractive index of material experienced a negative change when the pulse energy was above $10 \mathrm{~nJ}$, and the degree of the modification depended positively on the pulse energy. The size of laser-modified region increased with the increase in pulse energy. The threshold of refractive index modification under ultrafast laser irradiation was characterized to be about $863 \mathrm{~mJ} / \mathrm{cm}^{2}$.
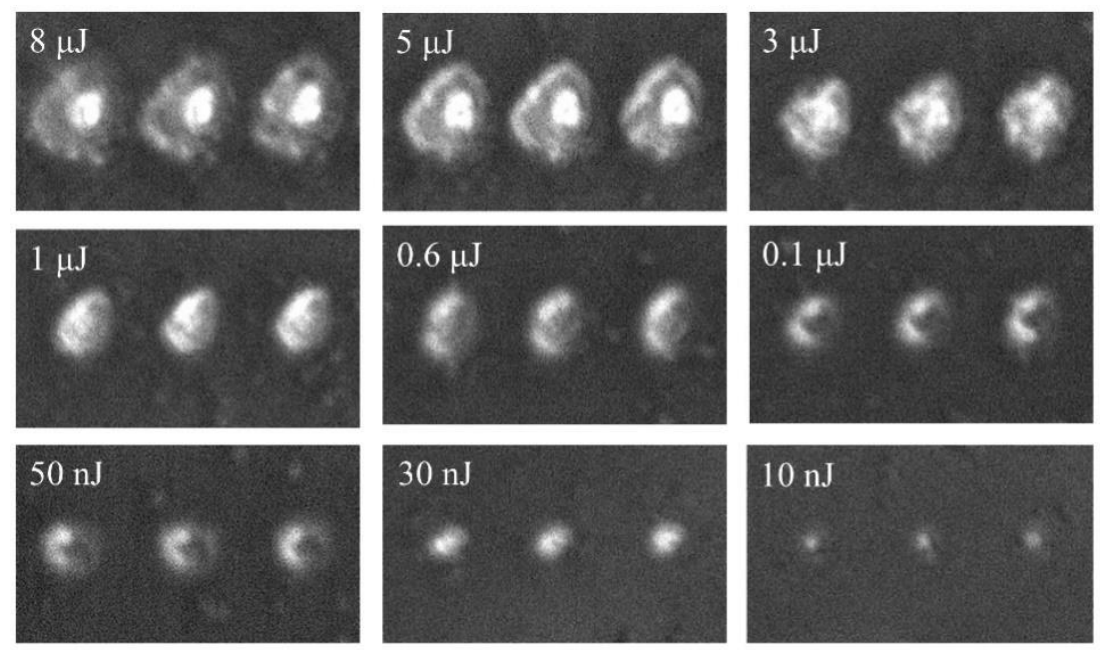

Figure 5. Phase contrast image of $\mathrm{V}_{2} \mathrm{O}_{5}$ after irradiated by ultrafast laser with different pulse energy. The focal beam waist is $697 \mathrm{~nm}$.

Local refractive index variation is the basis for optical devices such as waveguide and grating to produce optical function; therefore, it is very meaningful to study the refractive index modification of materials by ultrafast lasers. Since the focused ultrafast laser has an ultrahigh peak power intensity, which is enough to trigger the nonlinear absorption during laser-matter interaction, it results in local modification on material. The interaction between laser and matter is carried out through nonlinear effects within the focal length of the laser beam. After the sample was irradiated by ultrafast laser, most of the pulse energy was transferred to the material, which induced a series of refractive index modificationrelated processes, such as excitation and recombination. The natural phenomenon of laser irradiation weakens the strength of molecular bonds, which makes the material easier to expand and rarefact [23]. As the volume of the film expands, its density decreases, thus showing a negative refractive index change. This inference has been demonstrated in other papers; laser irradiation can form amorphous domains with lower density and, therefore, lower refractive index [24]. 
It is known from the previous $\mathrm{Z}$-scan results that the prepared $\mathrm{V}_{2} \mathrm{O}_{5}$ had self-defocus characteristics and a negative third-order nonlinear refractive index, which implies a maximum of the index decrease at the center of the beam; these results are shown in Figure 5. It is the first time to observe nonvolatile refractive index changes at vanadium oxide. At present, the research on ultrafast laser three-dimensional processing material structure modification is a hot topic, and will lay the foundation for the design and production of thin film material modified devices. It is possible to design novel devices combining nonvolatile and volatile index changes.

\subsection{Raman Analysis}

To analyze the structure changes of the film caused by different pulse energies, Raman spectra of different laser energy regions at room temperature were obtained by Confocal Micro-Raman spectrometer, which combines Raman spectrometer with microscopy, and could easily collect the spectra of a relatively small specific area of the film. Raman spectroscopy is very sensitive to the structure and the bond order of metal oxides, especially the stretching vibration mode of metal-oxygen bonds.

As shown in Figure 6, the results show peaks at 104, 147, 197, 284, 380, 418, 416, $530,646,703,751,902$, and $1000 \mathrm{~cm}^{-1}$. Compared with the unirradiated film (the curve corresponding to $0 \mathrm{~nJ}$ ), the redshift of the Raman spectrum indicates the presence of the stress in the film. When there is a stress in the film, the bond length will change, therefore the vibration frequency of the bond will change, resulting in the shift of the Raman spectra. Hence, the peak located at $418 \mathrm{~cm}^{-1}$ is offset from the peak at $416 \mathrm{~cm}^{-1}$.

(a)

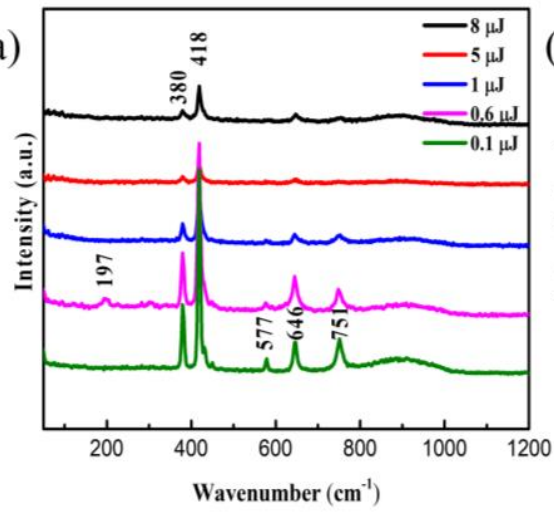

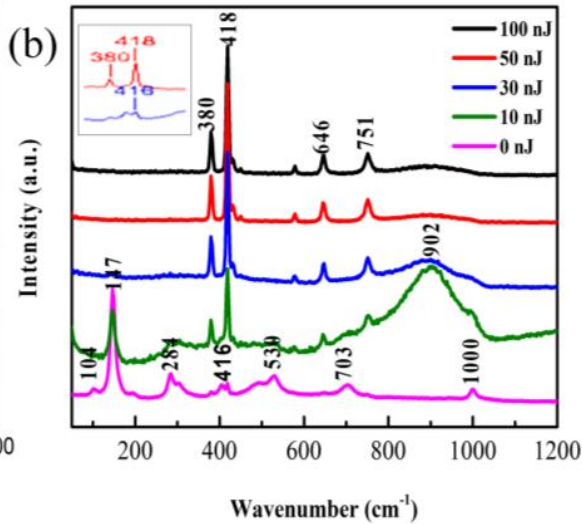

Figure 6. Raman spectra of $\mathrm{V}_{2} \mathrm{O}_{5}$ irradiated by high pulse energy (a) and low pulse energy (b). Inset shows the slightly shift of the peak at $416 \mathrm{~cm}^{-1}$.

The untreated film exhibits Raman peaks centered at 104, 147, 284, 416, 530, 703, and $1000 \mathrm{~cm}^{-1}$ and most of these peaks were in good accordance with the literature reported for vibration mode of oriented crystalline $\mathrm{V}_{2} \mathrm{O}_{5}$ [25]. The presence of the Raman peak at $1000 \mathrm{~cm}^{-1}$ is evidence for the $\mathrm{V}_{2} \mathrm{O}_{5}$ film layered structure corresponding to stretching vibration mode of the terminal oxygen $(\mathrm{V}=\mathrm{O})$, which arises from an unshared oxygen [26]. The peak at $703 \mathrm{~cm}^{-1}$ is attributed to the doubly coordinated oxygen (V-O2-V) stretching vibration mode which results from corner-shared oxygens common to the two pyramids $[25,27]$. The peak at $646 \mathrm{~cm}^{-1}$ is assigned to the stretching vibration mode of the V2-O bond [27]. The peak at $577 \mathrm{~cm}^{-1}$ corresponds to $\mathrm{VO}_{2}$ [28]. The peak at $530 \mathrm{~cm}^{-1}$ is assigned to the triply coordinated oxygen (V-O3) stretching vibration mode which results from edgedshared oxygens in common to the three pyramids $[27,29]$. The peak at $416 \mathrm{~cm}^{-1}$ is assigned to a V-O-V stretching vibration mode, which can be attributed to the $\mathrm{V}_{6} \mathrm{O}_{13}$ [30]. The peak at $380 \mathrm{~cm}^{-1}$ is assigned to the monoclinic $\mathrm{VO}_{2}$ (M1) phase, which represents the vibration mode of $\mathrm{V}-\mathrm{O}$ bond [31]. The peaks located at $284 \mathrm{~cm}^{-1}$ and $197 \mathrm{~cm}^{-1}$ are assigned to the bending vibration mode of the $\mathrm{O} 3-\mathrm{V}-\mathrm{O} 2$ bond [25]. The predominant peak at $147 \mathrm{~cm}^{-1}$ is assigned to the skeleton-bent vibration of the $\mathrm{V}-\mathrm{O}-\mathrm{V}$ bond, which can be observed in crys- 
talline $\mathrm{V}_{2} \mathrm{O}_{5}$ film $[27,30]$. The peak at $104 \mathrm{~cm}^{-1}$ is attributed to the external Ty mode [29]. The peaks at $751 \mathrm{~cm}^{-1}$ and near $902 \mathrm{~cm}^{-1}$ does not come from the $\mathrm{V}_{2} \mathrm{O}_{5}$, but from some of unidentified oxide of vanadium [28].

The Figure 6 shows that spectral peaks do not change significantly at irrdiated energy from $30 \mathrm{~nJ}$ to $8 \mu \mathrm{J}$. Instead, there are a distinct changes in some peak strength with the changes of energy. That means a stabile state. However, at low irridated dose in Figure $6 \mathrm{~b}$ the Raman spectra have big difference in compared with the initial vanadium oxide film. The Raman shifts indicates that the film is $\mathrm{V}_{2} \mathrm{O}_{5}$ [25]. After the irradiation with different pulse energies, the sample's oxidation state changed, making the Raman peak position shift. Comparing the spectrum of untreated film with that of the laser irradiated film, we found that the low-frequency Raman peaks at 104, 147, 197, and $284 \mathrm{~cm}^{-1}$, representing the lattice V-V vibrations [29], disappeared after laser exposure. In other words, the disappearance of these peaks may be caused by the break of the V-V bonds. In addition, the Raman spectrum in the region with the pulse energy of $10 \mathrm{~nJ}$ looks similar to that of the unirradiated $\mathrm{V}_{2} \mathrm{O}_{5}$ film, possibly due to the effect that the modified region by such a low energy pulse is too small to be accurately selected by the Confocal Micro-Raman spectrometer. Therefore, the result may contain a large contribution from the unirradiated film. Between 800 and $1000 \mathrm{~cm}^{-1}$, there is a broad band with a center position of about $902 \mathrm{~cm}^{-1}$, and this feature is present in all other irradiated Raman spectra. The broad Raman bands were considered to be the superimposition of multiple merging modes. The peaks at high frequency $\left(>800 \mathrm{~cm}^{-1}\right)$ were assigned to $\mathrm{V}=\mathrm{O}$ stretching vibration modes of distorted octahedra and distorted square-pyramids [32]. The new peaks at 751 and about $902 \mathrm{~cm}^{-1}$ did not correspond to any known vibrational mode of $\mathrm{V}_{2} \mathrm{O}_{5}$ and were explained to be associated with structural disorder [33]. In addition, the peak located at $902 \mathrm{~cm}^{-1}$ also appeared in other papers [30].

The Clausius-Mossotti equation told us that the refractive index of a solid is determined by the density of the constituent atoms and their corresponding polarizabilities [33]; laser irradiation will inevitably change the density of the irradiated region. In addition, the shift of the Raman spectra revealed that strain existed in the film, which led to a vibration of bonds length. Electron excitation is associated with the weakening and breaking of molecular bonds and formation of defects of color centers [23]. Each broken bond will produce a dangling bond or trigger a structure rearrangement process. Considering that the interaction between two oxygen atoms in the layered $\mathrm{V}_{2} \mathrm{O}_{5}$ film is relatively weak, the exsitence of oxygen vacancy and an oxygen dangling bond is also one of the important reasons for the refractive index modification.

The disappearance of initial peaks and the appearance of new peaks in the Raman spectrum indicated changes in the chemical composition of the irradiated region. Once the chemical composition changes, its physical properties including refractive index will inevitably change. In many optical glasses, the refractive index change is tightly associated with defect generation, bonds broken, and structure rearrangement [34]. Compared with optical glasses materials, $\mathrm{V}_{2} \mathrm{O}_{5}$ film possesses high nonlinear efficiency and relatively fragile, so changes in molecular structure occur more easily. In addition, the natural sapphire's Raman peaked at $418 \mathrm{~cm}^{-1}$ [35]. Therefore, it is possible that the structure change may also have been caused by the decrease in the thickness of the film after laser irradiated.

\section{Conclusions}

In conclusion, we have prepared the $\mathrm{V}_{2} \mathrm{O}_{5}$ films with different thicknesses by using the radio frequency $(\mathrm{RF})$ magnetron sputtering technique. The nonlinear absorption coefficient and the nonlinear refractive coefficient of the $90 \mathrm{~nm} \mathrm{~V}_{2} \mathrm{O}_{5}$ films were calculated to be $-338 \mathrm{~cm} / \mathrm{GW}$ and $-3.62 \times 10^{-12} \mathrm{~cm}^{2} / \mathrm{W}$, respectively. The saturated absorption properties of the $\mathrm{V}_{2} \mathrm{O}_{5}$ films exhibits excellent controllability when varying the film thickness. The modulation depth of film can be tuned from $13.8 \%$ to $29.3 \%$. Moreover, the refractive index modification by laser has been investigated and its physical mechanism has been 
discussed. The reasons for refractive index modification were the structure rearrangement (from $\mathrm{V}_{2} \mathrm{O}_{5}$ to $\mathrm{V}_{6} \mathrm{O}_{13}$ ), density variation, and defects. The progress of nanotechnology is largely dependent on the rapid development of ultrafast laser technology; the structural modification capability of ultrafast laser processing can reach nano-scale precision. Therefore, the research content of this paper is of great significance to optimize the performance of thin film optical devices.

Author Contributions: Conceptualization, Q.S. and Y.W.; methodology, Q.S. and G.C.; formal analysis, Y.W.; investigation, Q.S. and Y.L.; data curation, Q.S.; writing - original draft preparation, Q.S. and Y.L.; writing-review and editing, G.C. and G.Z.; supervision, G.C. and J.W.; project administration, G.C.; funding acquisition, G.C. and G.Z. All authors have read and agreed to the published version of the manuscript.

Funding: This research was funded by National Key Research and Development Program of China, grant number 2018YFB1107401, and National Natural Science Foundation of China, grant number 61775236 .

Institutional Review Board Statement: Not applicable.

Informed Consent Statement: Not applicable.

Data Availability Statement: Not applicable.

Conflicts of Interest: The authors declare no conflict of interest.

\section{References}

1. Jerominek, H.; Picard, F.; Vincent, D. Vanadium oxide films for optical switching and detection. Opt. Eng. 1993, 32, $2092-2099$. [CrossRef]

2. Katzke, H.; Tolédano, P.; Depmeier, W. Theory of morphotropic transformations in vanadium oxides. Phys. Rev. B 2003, 68, 024109. [CrossRef]

3. Kmper, A.; Hahndorf, I.; Baerns, M. A molecular mechanics study of the adsorption of ethane and propane on V2O5(001) surfaces with oxygen vacancies. Top. Catal. 2000, 11, 77-84. [CrossRef]

4. Xia, F.; Han, W.; Di, X.; Dubey, M.; Ramasubramaniam, A. Two-Dimensional Material Nanophotonics. Nat. Photonics 2014, 8, 899-907. [CrossRef]

5. Su, Q.; Lan, W.; Wang, Y.Y.; Liu, X.Q. Structural characterization of $\beta-\mathrm{V}_{2} \mathrm{O}_{5}$ films prepared by DC reactive magnetron sputtering. Appl. Surf. Sci. 2009, 255, 4177-4179. [CrossRef]

6. Guerra, E.M.; Silva, G.R.; Mulato, M. Extended gate field effect transistor using $\mathrm{V}_{2} \mathrm{O}_{5}$ xerogel sensing membrane by sol-gel method. Solid State Sci. 2009, 11, 456-460. [CrossRef]

7. Song, G.Y.; Oh, C.; Sinha, S.; Son, J.; Heo, J. Facile phase control of multivalent vanadium oxide thin films $\left(\mathrm{V}_{2} \mathrm{O}_{5}\right.$ and $\left.\mathrm{VO}_{2}\right)$ by atomic layer deposition and postdeposition annealing. ACS Appl. Mater. Interfaces 2017, 9, 23909-23917. [CrossRef]

8. Vernardou, D.; Spanakis, E.; Kenanakis, G.; Koudoumas, E.; Katsarakis, N. Hydrothermal growth of V2O5 photoactive films at low temperature. Mater. Chem. Phys. 2010, 124, 319-322. [CrossRef]

9. Livshits, P.; Inberg, A.; Shacham-Diamand, Y.; Malka, D.; Fleger, Y.; Zalevsky, Z. Precipitation of gold nanoparticles on insulating surfaces for metallic ultra-thin film electroless deposition assistance. Appl. Surf. Sci. 2012, 258, 7503-7506. [CrossRef]

10. Stoian, R.; Bhuyan, M.K.; Rudenko, A.; Colombier, J.P.; Cheng, G. High-resolution material structuring using ultrafast laser non-diffractive beams. Adv. Phys. X 2019, 4, 1659180. [CrossRef]

11. Gerasimenko, A.Y.; Kuksin, A.V.; Shaman, Y.P.; Kitsyuk, E.P.; Fedorova, Y.O.; Sysa, A.V.; Pavlov, A.A.; Glukhova, O.E. Electrically Conductive Networks from Hybrids of Carbon Nanotubes and Graphene Created by Laser Radiation. Nanomaterials 2021, 11, 1875. [CrossRef]

12. Je, G.; Malka, D.; Kim, H.; Hong, S.; Shin, B. A study on micro hydroforming using shock wave of $355 \mathrm{~nm}$ UV-pulsed laser. Appl. Surf. Sci. 2017, 417, 244-249. [CrossRef]

13. Kürüm, U.; Öksüzoğlu, R.M.; Yüksek, M.; Yaglioglu, H.G.; Çınar, H.; Elmali, A. The third order nonlinear optical characteristics of amorphous vanadium oxide thin film. Appl. Phys. A 2011, 104, 1025-1030. [CrossRef]

14. Long, H.; Tao, L.; Tang, C.Y.; Zhou, B.; Zhao, Y.; Zeng, L.; Yu, S.F.; Lau, S.P.; Chai, Y.; Tsang, Y.H. Tuning nonlinear optical absorption properties of WS2 nanosheets. Nanoscale 2015, 7, 17771-17777. [CrossRef] [PubMed]

15. Wang, K.; Feng, Y.; Chang, C.; Zhan, J.; Wang, C.; Zhao, Q.; Coleman, J.N.; Zhang, L.; Blau, W.J.; Wang, J. Broadband ultrafast nonlinear absorption and nonlinear refraction of layered molybdenum dichalcogenide semiconductors. Nanoscale 2014, 6, 10530-10535. [CrossRef]

16. Butt, F.K.; Cao, C.; Idrees, F.; Tahir, M.; Alshemary, A.Z. Fabrication of $\mathrm{V}_{2} \mathrm{O}_{5}$ Super Long Nanobelts: Their Optical, In-Situ Electrical and Field Emission Properties. New J. Chem. 2015, 39, 5197-5202. [CrossRef] 
17. Bera, B.; Esther, A.C.M.; Dey, A.; Mukhopadhyay, A.K. Structural, optical and electrical properties of $\mathrm{V}_{2} \mathrm{O}_{5}$ xerogel thin films. Indian J. Phys. 2016, 90, 687-692. [CrossRef]

18. Sucharitakul, S.; Ye, G.; Lambrecht, W.R.L.; Bhandari, C.; Gross, A.; He, R.; Poelman, H.; Gao, X.P.A. V2 O5: A 2D vander Waals Oxide with Strong In-Plane Electrical and Optical Anisotropy. ACS Appl. Mater. Interfaces 2017, 9, 23949-23956. [CrossRef] [PubMed]

19. Bhupathi, S.; Wang, S.; Abutoama, M.; Balin, I.; Wang, L.; Kazansky, P.G.; Abdulhalim, I. Femtosecond Laser-Induced Vanadium Oxide Metamaterial Nanostructures and the Study of Optical Response by Experiments and Numerical Simulations. ACS Appl. Mater. Interfaces 2020, 12, 41905-41918. [CrossRef]

20. Sheikbahae, M.; Said, A.A.; Wei, T.H.; Wu, Y.Y.; Hagan, D.J.; Soileau, M.J.; Stryland, E.W.V. Z-Scan: A Simple and Sensitive Technique For Nonlinear Refraction Measurements. Proc. SPIE 1989, 1148, 41.

21. Htwe, Z.M.; Zhang, Y.D.; Yao, C.B.; Li, H.; Li, H.Y.; Yuan, P. Investigation of third order nonlinear optical properties of undoped and indium doped zinc oxide (InZnO) thin films by nanosecond Z-scan technique. Opt. Mater. 2016, 52, 6-13. [CrossRef]

22. Nagaraja, K.K.; Pramodini, S.; Kumar, A.S.; Nagaraja, H.S.; Poornesh, P.; Kekuda, D. Third-order nonlinear optical properties of Mn doped $\mathrm{ZnO}$ thin films under cw laser illumination. Opt. Mater. 2013, 35, 431-439. [CrossRef]

23. Stoian, R. Volume photoinscription of glasses: Three-dimensional micro- and nanostructuring with ultrashort laser pulses. Appl. Phys. A 2020, 126, 438. [CrossRef]

24. Gorelik, T.; Will, M.; Nolte, S.; Tünnermann, A.; Glatzel, U. Transmission electron microscopy studies of femtosecond laser induced modifications in quartz. Appl. Phys. A Mater. Sci. Process. 2003, 76, 309-311. [CrossRef]

25. Baddour-Hadjean, R.; Golabkan, V.; Pereira-Ramos, J.P.; Mantoux, A.; Lincot, D. A Raman study of the lithium insertion process in vanadium pentoxide thin films deposited by atomic layer deposition. J. Raman. Spectrosc. 2010, 33, 631-638. [CrossRef]

26. Clark, R.J.H. The Chemistry of Titanium and Vanadium: An. Introduction to the Chemistry of the Early Transition Elements; Elsevier: Amsterdam, The Netherlands, 1968.

27. Lee, S.H.; Cheong, H.M.; Seong, M.J.; Liu, P.; Tracy, C.E.; Mascarenhas, A.; Pitts, J.R.; Deb, S.K. Raman spectroscopic studies of amorphous vanadium oxide thin films. Solid. State. Ion. 2003, 15, 111-116. [CrossRef]

28. Ureña-Begara, F.; Crunteanu, A.; Raskin, J.P. Raman and XPS characterization of vanadium oxide thin films with temperature. Appl. Surf. Sci. 2017, 403, 717-727. [CrossRef]

29. Abello, L.; Husson, E.; Repelin, Y.; Lucazeau, G. Vibrational spectra and valence force field of crystalline $\mathrm{V}_{2} \mathrm{O}_{5}$. Spectrochim. Acta. A Mol. Spectrosc. 1983, 39, 641-651. [CrossRef]

30. Wang, X.J.; Li, H.D.; Fei, Y.J.; Wang, X.; Xiong, Y.Y.; Nie, Y.X.; Feng, K.A. XRD and Raman study of vanadium oxide thin films deposited on fused silica substrates by RF magnetron sputtering. Appl. Surf. Sci. 2001, 177, 8-14. [CrossRef]

31. Prasadam, V.P.; Dey, B.; Bulou, S.; Schenk, T.; Bahlawane, N. Study of $\mathrm{VO}_{2}$ thin film synthesis by atomic layer deposition. Mater. Today Chem. 2019, 12, 332-342. [CrossRef]

32. Lee, S.; Ivanov, I.N.; Keum, J.K.; Lee, H.N. Polymorphs. Sci. Rep. 2016, 6, 073112.

33. Bouzidi, A.; Benramdane, N.; Bresson, S.; Mathieu, C.; Desfeux, R.; Marssi, M.E. X-ray and Raman study of spray pyrolysed vanadium oxide thin films. Vib. Spectrosc. 2011, 57, 182-186. [CrossRef]

34. Mishchik, K.; Ferrer, A.; Cruz, A.; Mermillodblondin, A.; Mauclair, C.; Ouerdane, Y.; Boukenter, A.; Stoian, R. Photoinscription domains for ultrafast laser writing of refractive index changes in BK7 borosilicate crown optical glass. Opt. Mater. Express 2012, 3, 67-85. [CrossRef]

35. Ferraro, J.R.; Skelton, E.F. Vibrational Spectroscopy at High External Pressures: The Diamond Anvil Cell. Phys. Today 1984, 39, 62-64. [CrossRef] 